\title{
Hospital Readmission and Emergency Department Revisits of Homeless Patients Treated at Homeless-Serving Hospitals in the USA: Observational Study
}

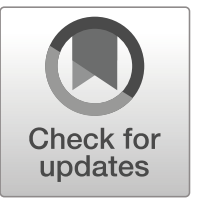

\author{
Atsushi Miyawaki, MD, $\mathrm{PhD}^{1,2} \mathbb{D}_{\mathrm{D}}$, Kohei Hasegawa, $\mathrm{MD}, \mathrm{MPH}^{3,4}$, \\ Jose F. Figueroa, $M D, M P H^{5,6}$, and Yusuke Tsugawa, $M D, P h D^{7,8}$
}

'Department of Public Health, Graduate School of Medicine, The University of TokyoTokyo, Japan; ${ }^{2}$ Health Services Research Development Center, University of TsukubaTsukuba, Ibaraki, Japan; ${ }^{3}$ Department of Emergency Medicine, Massachusetts General HospitalBoston, MA, USA; ${ }^{4}$ Harvard Medical SchoolBoston, MA, USA; ${ }^{5}$ Department of Health Policy and Management, Harvard T.H. Chan School of Public HealthBoston, MA, USA; ${ }^{6}$ Department of Medicine, Brigham and Women's HospitalBoston, MA, USA; ${ }^{7}$ Division of General Internal Medicine and Health Services Research, UCLA David Geffen School of Medicine Los Angeles, CA, USA; ${ }^{8}$ Department of Health Policy and Management, UCLA Fielding School of Public HealthLos Angeles, CA, USA.

BACKGROUND: As the U.S. homeless population grows, so has the challenge of providing effective care to homeless individuals. Understanding hospitals that achieve better outcomes after hospital discharge for homeless patients has important implications for making our health system more sustainable and equitable.

OBJECTIVE: To determine whether homeless patients experience higher rates of readmissions and emergency department (ED) visits after hospital discharge than nonhomeless patients, and whether the homeless patients exhibit lower rates of readmissions and ED visits after hospital discharge when they were admitted to hospitals experienced with the treatment of the homeless patients ("homeless-serving" hospitals-defined as hospitals in the top decile of the proportion of homeless patients).

DESIGN: A population-based longitudinal study, using the data including all hospital admissions and ED visits in FL, MA, MD, and NY in 2014.

PARTICIPANTS: Participants were 3,527,383 patients (median age [IGR]: 63 [49-77] years; 1,876,466 [53\%] women; 134,755 [4\%] homeless patients) discharged from 474 hospitals.

MAIN MEASURES: Risk-adjusted rates of 30-day allcause readmissions and ED visits after hospital discharge.

KEY RESULTS: After adjusting for potential confounders, homeless patients had higher rates of readmissions (adjusted rate, $27.3 \%$ vs. $17.5 \%$; adjusted odds ratio [aOR], 1.93; 95\% CI, 1.69-2.21; $p<0.001)$ and ED visits after hospital discharge (37.1\% vs. $23.6 \%$; aOR, 1.98; 95\% CI, 1.74-2.25; $p<0.001)$ compared with non-homeless patients. Homeless patients treated at homeless-serving hospitals exhibited lower rates of readmissions (23.9\% vs. $33.4 \% ; p<0.001$ ) and ED visits (31.4\% vs. $45.4 \% ; p<$ $0.001)$ after hospital discharge than homeless patients treated at non-homeless-serving hospitals.

Electronic supplementary material The online version of this article (https://doi.org/10.1007/s11606-020-06029-0) contains supplementary material, which is available to authorized users.

Received October 17, 2019

Accepted June 30, 2020

Published online July 14, 2020
CONCLUSIONS: Homeless patients were more likely to be readmitted or return to $\mathrm{ED}$ within 30 days after hospital discharge, especially when they were treated at hospitals that treat a small proportion of homeless patients. These findings suggest that homeless patients may receive better discharge planning and care coordination when treated at hospitals experienced with caring for homeless people.

KEY WORDS: homeless patients; quality of care; hospital quality; readmission; emergency department visit.

$J$ Gen Intern Med 35(9):2560-8

DOI: $10.1007 / \mathrm{s} 11606-020-06029-0$

(c) Society of General Internal Medicine 2020

\section{INTRODUCTION}

The number of homeless people in the USA has been rapidly increasing, ${ }^{1-3}$ and an estimated 2.5 to 3.5 million Americans are experiencing homelessness annually. ${ }^{4}$ The homeless populations incur a higher burden of diseases such as mental illness and substance use disorder ${ }^{5}$ and are more likely to face issues related to socio-economic factors - including lack of social support, limited financial resources, and increased exposure to environmental risks - that make them particularly vulnerable for experiencing increased morbidity and mortality. As the homeless population continues to grow, it is becoming increasingly challenging for policymakers and the health system to adequately and fully address care for these patients, especially as many of them rely on hospitals not only for medical care but also for shelter and food. ${ }^{6}$

To date, there is limited evidence documenting higher rates of hospital or emergency department (ED) revisit rates for homeless patients shortly after discharge from hospitals. However, existing research is limited to studies conducted in a single city, ${ }^{7-10}$ and it remains unclear how generalizable these findings are to other regions in the USA. High rates of revisits among the homeless 
population following a hospitalization-which include hospital readmission or a return to the ED without requiring an admission - are quite costly to the U.S. health care system, and they may reflect suboptimal quality of care delivered to these patients or other unmet needs. ${ }^{11,12}$ Recognizing the importance of preventing revisit rates to hospitals, federal and state governments have introduced programs and policies to enhance care coordination and discharge planning through mandatory national hospital penalty programs, including the Hospital Readmissions Reduction Program (HRRP). ${ }^{13}$ Some states implemented policies to directly target the revisits of the homeless population. For example, starting July 1, 2019, California requires hospitals to provide written plans for coordination of services and referrals to social service agencies to homeless patients at discharge. ${ }^{14}$

The quality of care homeless patients receive at hospitals may play a key role in determining homeless patients' risk of readmissions and ED visits after hospital discharge. Prior studies have shown wide variations in the rates of readmissions and ED visit after hospital discharge among the general patient population across U.S. hospitals, ${ }^{15}, 16$ much of which is likely influenced by the quality of discharge planning and care coordination, which includes ensuring appropriate and timely follow-up with ambulatory providers. ${ }^{17}$ However, little is known about whether such variations exist for the care of the homeless population, and the characteristics of hospitals that achieve lower rates of readmissions and ED visits after hospital discharge. It is possible that hospitals that serve a high proportion of homeless patients may invest in specific resources or programs that can help assist with the transition from the hospital to the community. ${ }^{18}$ On the other hand, hospitals that serve few homeless patients may not necessarily invest sufficient resources or direct efforts at meaningfully improving transitions of care to the community setting for this vulnerable population. It is critically important for policymakers to understand the mechanisms as to why homeless patients are returning to hospitals so frequently, and the characteristics of hospitals that treat a large number of homeless patients, to design interventions that can effectively reduce readmissions and ED visits after the discharge of the homeless population. ${ }^{19}$

Therefore, in this study, using the state database of all hospital admissions and ED visits in four large and diverse states, we sought to answer the following three key questions. First, are there meaningful differences in the rates of 30-day readmissions and ED visits after discharge between homeless and non-homeless patients? Second, what are the characteristics of hospitals that serve a high proportion of homeless patients? Finally, are there substantial differences in the rates of readmissions and ED visits after hospital discharge between the hospitals that serve a large proportion of homeless people relative to those who serve less?

\section{METHODS}

\section{Study Design, Setting, and Data Sources}

We analyzed the 2014 State Inpatient Database (SID) and State Emergency Department Databases (SEDD) of four states: Florida, Maryland, Massachusetts, and New York. These data were collected at each state in the Healthcare Cost and Utilization Project of the Agency for Healthcare Research and Quality (AHRQ). ${ }^{20,}{ }^{21}$ The SID includes all the inpatient discharge records from community hospitals (short-term hospitals accessible by the general public, including academic medical centers), regardless of the source of hospital admission; and the SEDD includes all the discharge records on ED visits at hospital-affiliated EDs that did not result in hospital admission. Taken together, these data include all patients who were admitted to a hospital or presented to ED in a given state. We selected these four states because of their socio-demographic diversity of the population and the availability of the homeless indicator (only seven states [four states included in our analysis plus Georgia, Utah, and Wisconsin] included both the homeless indicator and a unique patient linkage number for SID/SEDD. Three states were not included in our analyses because our internal investigation identified an underreporting of the homeless indicator for Utah and Wisconsin, and the hospital identifier was not available for Georgia).

We identified all adults aged 18 years or older who were admitted to the acute care hospitals in these four states in 2014 and then examined their rates of readmissions and ED visits after discharge. Discharges occurring in December 2014 for $\mathrm{MA}$ and NY, and the last quarter for MD and FL, were excluded to ensure a full 30 days of follow-up (as only information on discharge quarter was available for MD and FL [and the data on discharge month were unavailable]). From the 4,519,374 hospitalizations in our initial sample, we excluded 193,877 hospitalizations (4.3\%) of patients who died in the hospital or were discharged against medical advice; 450,394 hospitalizations $(10.0 \%)$ with the primary discharge diagnoses related to delivery (Clinical Classification Software [CCS] single-level codes: 177-192, 194-196, 218-220, or 222-224); and 347,720 (7.7\%) hospitalizations with missing data on key variables. Our final analytic sample consisted of 3,527,383 hospital discharges.

To obtain information on the hospital characteristics, we linked the SID/SEDD with the 2016 American Hospital Association Annual Survey database ${ }^{22}$ to identify information on several hospital characteristics: profit status, Rural-Urban Commuting Area (RUCA) classification, teaching status, hospital size, the presence of medical intensive care unit (MICU) or cardiac intensive care unit (CICU), and the proportion of hospitalized patients with Medicaid or Medicare.

\section{Exposure Variables}

The primary exposure variables of interest were (1) homeless status and (2) the site of care. The SID/SEDD 
provides the indicator variable for the homeless status that was directly reported by hospitals, as has been used in reports by the AHRQ ${ }^{23,24}$ and in prior research. ${ }^{5}$ In this study, patients recorded as homeless any time in 2014 were defined as homeless (period prevalence counts rather than point-in-time counts) to account for the dynamic status of the homelessness and to focus on the groups whose access to secured housing was not guaranteed. ${ }^{4}$

As for the site of care, we calculated the proportion of homeless patients for each hospital and categorized hospitals in the highest decile of the proportion of homeless patients as homeless-serving hospitals (HSH). The remaining $90 \%$ of hospitals were categorized as nonHSH. A similar approach has been used to identify minority-serving hospitals in previous studies. ${ }^{25,} 26$

\section{Outcome Variables}

Our outcome variables of interest were (1) 30-day allcause readmission captured according to the methodology recommended by the $\operatorname{HCUP}^{27}$ and (2) 30-day all-cause ED visit after hospital discharge.

\section{Adjustment Variables}

We adjusted for the potential confounders: patient characteristics, discharge disposition, length of stay (LOS), and hospital characteristics. Patient characteristics included the primary diagnosis for the admission (an indicator variable for Medicare Severity Diagnosis Related Group [MSDRG] codes), age at the point of admission (18-29, 30$39,40-49,50-59,60-69,70-79$, and 80 years or older), sex, race/ethnicity (Non-Hispanic White, Non-Hispanic Black, Hispanic, and others), primary payers (Medicare, Medicaid, private insurance, self-pay, and others), and the indicator variables for 29 comorbidities included in the Elixhauser comorbidity index. ${ }^{28}$

Discharge disposition was categorized as routine discharge, transfer to skilled nursing facility/intermediate care facility, home health care, and others. LOS was used as a continuous variable. Hospital characteristics included profit status (forprofit, non-profit, and public), RUCA (urban, suburban, large rural, and small rural), teaching status (major, minor, and nonteaching), hospital size (large [400+ beds], medium [100-399 beds], and small [1-99 beds]), and the presence of $\mathrm{MICU} / \mathrm{CICU}$.

\section{Statistical Analysis}

First, we compared the characteristics of homeless patients vs. non-homeless patients and hospital characteristics of HSH and non-HSH.

Second, we examined how the rates of readmission and ED visit differ by the homeless status (homeless vs. nonhomeless) of patients and by the site of care (HSH vs. non-HSH). We constructed two regression models to control for potential confounders. Model 1 was adjusted for patient characteristics, and quarter and state indicator variables (i.e., dummy variables for quarter and state, effectively comparing patients within the same quarter and state). Model 2 was adjusted for all the variables included in Model 1 plus hospital characteristics, discharge location, and LOS, to investigate if these factors explain the observed differences in patient outcomes. We used multivariable logistic regression models, with standard errors clustered at hospital level to account for a potential correlation of patients treated at the same hospital. To calculate risk-adjusted rates of 30-day readmission and ED visit, we used marginal standardization (i.e., predictive margins or margins of responses). For each hospital discharge, we calculated predicted probabilities of patient readmission and ED visit with either homeless status or homeless-serving status fixed at each category and then averaged over the distribution of covariates in our sample. $^{29}$

Finally, using the same regression models, we examined whether patient outcomes between the homeless and non-homeless patients vary by the site of care, by including the interaction term between the homeless status and $\mathrm{HSH}$ in our regression models. We used a Wald test adjusted for clustering (to approximate a likelihood ratio test because standard likelihood-based tests are not available with the clustered data) to formally test the interaction between the homeless status and $\mathrm{HSH} .{ }^{30}$ For each of four patient groups (homeless patients at $\mathrm{HSH}$, nonhomeless patients at $\mathrm{HSH}$, homeless patients at non$\mathrm{HSH}$, and non-homeless patients at non-HSH), we calculated the risk-adjusted rates of 30-day readmission and ED visit using marginal standardization. To account for multiple comparisons (six pair-wise comparisons between four groups), we considered two-tailed $p$ value $<0.0083$ to be statistically significant.

\section{Sensitivity Analyses}

We conducted a series of sensitivity analyses. First, to examine whether the observed relationships depend on our threshold for defining HSH, we used an alternative definition, the highest quintile, to define HSH. Second, we tested whether our findings vary based on the primary diagnosis of hospital admissions. We selected four major conditions in our data and also used as target conditions in the HRRP ${ }^{13}$ : acute myocardial infarction (AMI) (CCS single-level code: 100), pneumonia (108), chronic obstructive pulmonary disease (COPD) (122), and heart failure (HF) (127). We used the same regression models except for including the primary diagnosis as an adjustment variable.

All analyses were conducted using Stata version 15 (College Station, TX; StataCorp LLC.). ${ }^{31}$ The study was approved by the UCLA Institutional Review Board. 
Table 1 Patient Characteristics by Homeless Status

\begin{tabular}{|c|c|c|c|c|}
\hline & & \multicolumn{2}{|c|}{ No. (\%) of hospital discharges } & \multirow[t]{2}{*}{$p$ values } \\
\hline & & Homeless & Non-homeless & \\
\hline \multicolumn{2}{|c|}{ Total number of discharges } & 134,755 & $3,392,628$ & \\
\hline \multicolumn{2}{|c|}{ Age, median (IQR), year } & $51(38-62)$ & $64(49-77)$ & $<0.001$ \\
\hline \multirow{2}{*}{\multicolumn{2}{|c|}{$\begin{array}{l}\text { Female sex } \\
\text { Race/Ethnicity }\end{array}$}} & $54,331(40)$ & $1,822,135(54)$ & $<0.001$ \\
\hline & Non-Hispanic White & $40,301(30)$ & $2,277,500(67)$ & $<0.001$ \\
\hline & Non-Hispanic Black & $44,563(33)$ & $547,637(16)$ & \\
\hline & Hispanic & $30,380(23)$ & $361,557(11)$ & \\
\hline & Others & $19,511(15)$ & $205,934(6)$ & \\
\hline \multirow[t]{5}{*}{ Payer } & Medicare & $40,205(30)$ & $1,858,952(55)$ & $<0.001$ \\
\hline & Medicaid & $77,616(58)$ & $496,184(15)$ & \\
\hline & Private insurance & $5283(4)$ & $784,264(23)$ & \\
\hline & Self-pay & $7578(6)$ & $128,735(4)$ & \\
\hline & Others & $4073(3)$ & $124,493(4)$ & \\
\hline \multicolumn{5}{|l|}{ Comorbidities } \\
\hline \multicolumn{2}{|l|}{ Diabetes } & $34,309(25)$ & $935,550(28)$ & $<0.001$ \\
\hline \multicolumn{2}{|l|}{ Hypertension } & $61,621(46)$ & $2,032,263(60)$ & $<0.001$ \\
\hline \multicolumn{2}{|c|}{ Chronic kidney disease } & $12,733(9)$ & $529,074(16)$ & $<0.001$ \\
\hline \multicolumn{2}{|c|}{ Chronic pulmonary disease } & $30,724(23)$ & $866,316(26)$ & $<0.001$ \\
\hline \multicolumn{2}{|c|}{ Valvular heart disease } & $3690(3)$ & $269,977(8)$ & $<0.001$ \\
\hline \multicolumn{2}{|c|}{ Peripheral vascular disease } & $4168(3)$ & $242,711(7)$ & $<0.001$ \\
\hline \multicolumn{2}{|c|}{ Depression } & $25,105(19)$ & $560,424(17)$ & $<0.001$ \\
\hline \multicolumn{2}{|l|}{ Obesity } & $14,271(11)$ & $488,713(14)$ & $<0.001$ \\
\hline \multicolumn{2}{|l|}{ Alcohol abuse } & $34,196(25)$ & $242,987(7)$ & $<0.001$ \\
\hline \multicolumn{2}{|l|}{ Drug abuse } & $34,826(26)$ & $226,078(7)$ & $<0.001$ \\
\hline
\end{tabular}

$p$ values are calculated using rank-sum test for continuous variables and chi-square test for categorical variables. The primary diagnosis for the admission (based on Medicare Severity Diagnosis Related Group) was not shown in this table because it consisted of too many dummy variables. Selected comorbidities are shown

\section{RESULTS}

\section{Patient Characteristics}

Of the $3,527,383$ analytic inpatients, $134,755(3.8 \%)$ were identified as homeless. Homeless patients were younger, more likely to be male, racial and ethnic minority, experiencing alcohol abuse and drug abuse than non-homeless patients, and more likely to be enrolled in Medicaid (Table 1).

\section{Characteristics of HSH and non-HSH}

The sites where homeless patients received inpatient care were disproportionately concentrated as shown in Figure A1 and Table 2. HSH were more likely to be public, teaching hospitals located in an urban area. HSH provided care to a lower proportion of Medicare patients and a higher proportion of Medicaid patients than non-HSH. The hospital size and presence of MICU/CICU did not significantly differ by homelessserving status.

\section{Readmissions and ED Visits by Homeless Status and Site of Care}

Overall, homeless patients had higher rates of 30-day readmissions (adjusted readmission rate, $27.3 \%$ vs. $17.5 \%$; adjusted odds ratio [aOR], 1.93; 95\% confidence interval [CI], 1.69$2.21 ; p<0.001$ ) and $\mathrm{ED}$ visits (adjusted $\mathrm{ED}$ visit rate, $37.1 \%$ vs. $23.6 \%$; aOR, $1.98 ; 95 \%$ CI, $1.74-2.25 ; p<0.001)$ after hospital discharge compared with non-homeless patients, after adjusting for potential confounders (Model 1) (Table 3). For the analysis of all hospitalized patients (including both homeless and non-homeless patients), we found no evidence that patients' readmission rates differed between HSH and non-HSH $(17.9 \%$ for HSH vs. $18.0 \%$ for non-HSH; aOR, $0.99 ; 95 \% \mathrm{CI}, 0.89-1.09 ; p=0.83$ ), whereas the rate of ED visits after hospital discharge was slightly lower for $\mathrm{HSH}$ ( $22.9 \%$ vs. $24.4 \%$; aOR, $0.92 ; 95 \%$ CI, $0.86-0.98 ; p=0.01$ ). These associations did not change qualitatively after additional adjustment for hospital characteristics, discharge location, and LOS in Model 2.

\section{Homelessness with Readmissions and ED Visits by the Site of Care}

Homeless patients treated at HSH had lower rates of readmissions $(23.9 \%$ vs. $33.4 \%$; aOR, 0.58 ; $95 \%$ CI, $0.47-0.71 ; p<$ $0.001)$ and $\mathrm{ED}$ visits $(31.4 \%$ vs. $45.4 \%$; aOR, $0.53 ; 95 \% \mathrm{CI}$, $0.45-0.62 ; p<0.001)$ after hospital discharge compared with homeless patients treated at non-HSH (Fig. 1; Model 1 in Table A1). We found no evidence that rates of readmission and ED revisit after hospital discharge of non-homeless patients differed between HSH and non-HSH. The formal test of interaction between homeless status and the site of care was statistically significant for both outcome variables $(p<0.001)$. These findings were unaffected by additional adjustments for hospital characteristics, discharge location, and LOS in Model 2 (Table A1).

\section{Sensitivity Analyses}

Our findings were largely unchanged by using alternative cut points for defining HSH (using the highest quintile 
Table 2 Hospital Characteristics by Type of Hospital

\begin{tabular}{|c|c|c|c|}
\hline & Homeless-serving hospitals $(n=47)$ & Non-homeless-serving hospitals $(n=427)$ & $p$ value \\
\hline & Hospital characteristics, no. (\%) & & \\
\hline \multicolumn{4}{|l|}{ Hospital size } \\
\hline Large (400+ beds) & $14(30)$ & $78(18)$ & \multirow[t]{3}{*}{0.12} \\
\hline Medium (100-399 beds) & $21(45)$ & $246(58)$ & \\
\hline Small (1-99 beds) & $12(26)$ & $103(24)$ & \\
\hline \multicolumn{4}{|l|}{ Teaching status } \\
\hline Major & $11(23)$ & $39(9)$ & \multirow[t]{3}{*}{$<0.001$} \\
\hline Minor & $22(37)$ & $129(30)$ & \\
\hline Non-teaching & $14(30)$ & $259(61)$ & \\
\hline \multicolumn{4}{|l|}{ Profit status } \\
\hline For-profit & $8(17)$ & $115(27)$ & \multirow[t]{3}{*}{$<0.001$} \\
\hline Non-profit & $24(51)$ & $281(66)$ & \\
\hline Public & $15(32)$ & $31(7)$ & \\
\hline \multicolumn{4}{|l|}{ RUCA } \\
\hline Urban & $46(98)$ & $342(80)$ & \multirow[t]{4}{*}{0.03} \\
\hline Suburban & $0(0)$ & $26(6)$ & \\
\hline Large rural & $1(2)$ & $37(9)$ & \\
\hline Small rural & $0(0)$ & $22(5)$ & \\
\hline Medical ICU & $32(68)$ & $284(67)$ & 0.83 \\
\hline \multirow{2}{*}{ Cardiac ICU } & $22(47)$ & $157(37)$ & 0.18 \\
\hline & Patient population, median (IQR), \% & & \\
\hline Homeless patients & $22(15-70)$ & $2(1-5)$ & $<0.001$ \\
\hline Medicare patients & $27(21-43)$ & $49(43-56)$ & $<0.001$ \\
\hline Medicaid patients & $28(17-60)$ & $13(19-24)$ & $<0.001$ \\
\hline
\end{tabular}

$p$ values are calculated using rank-sum test for continuous variables and chi-square test for categorical variables

[Table A2]) and consistent across four major primary diagnoses (Tables A3 and A4).

\section{DISCUSSION}

Using the state data of all hospital admissions and ED visits from four large and diverse states in the USA, we found that homeless patients exhibited a higher likelihood of 30-day readmissions and ED visits after hospital discharge compared with non-homeless patients and that homeless patients discharged from hospitals that treat a large proportion of homeless patients had a lower probability of readmissions and ED visits after hospital discharge compared with homeless patients discharged from other hospitals. These findings suggest that homeless patients are incurring a higher burden of readmissions and ED visits after discharge possibly due to suboptimal quality of coordination and planning at discharge. ${ }^{32-34}$ Our findings shed light on the importance of hospitals that are more experienced with caring for homeless patients - which may be providing better discharge planning and care coordination represented by their lower rates of revisits after hospital discharge - indicating that other hospitals may be able to learn from the care delivery process delivered by these high-performing hospitals.

There are several potential mechanisms through which the homeless populations experience a higher burden of readmissions and ED visits after hospital discharge. First, the homeless populations often confront a barrier to appropriate postdischarge care because of competing priorities such as obtaining food, clothing, and shelter/housing; have limited access to the primary care provider and specialty follow-up care after discharge due to lack of appropriate insurance coverage; and lack financial and/or social resources to continue maintenance therapies. ${ }^{34-36}$ They may also face difficulty purchasing, storing, and taking appropriate medications, or installing or maintaining medical devices such as oxygen equipment. ${ }^{37}$ Second, the environment of living on the street or in a shelter may have detrimental effects on their pre-existing health conditions (e.g., infections, cold- and heat-related illnesses and injuries) or cause new health problems. ${ }^{38}$ Violence and injuries are additional major risk factors for readmissions and ED visits to which the homeless population is more vulnerable. ${ }^{39}$ Third, homeless patients often have comorbidities, such as substance use disorders and mental health problems, that are associated with a higher risk of readmissions and ED visits after hospital discharge. ${ }^{5,40,41}$ Fourth, it is also possible that low educational level or health literacy and lack of dependable communication between patients and providers that are more common among homeless patients might cause poorer discharge planning and care coordination, leading to higher rates of readmission and ED revisit after hospital discharge. ${ }^{34}$ Finally, the homeless patients may return to hospitals and EDs not to seek medical care, but to seek shelter, housing, and meals, and thus, are likely to return to hospitals after discharge regardless of their health conditions. ${ }^{42}$

We also found that homeless patients exhibited a lower risk of readmissions and ED visits when they were discharged from hospitals that treat a high proportion of homeless patients (HSH). Although hospitals that treat a large number of homeless patients may face financial constraints due to uncompensated care, ${ }^{43}$ these hospitals may learn from their accumulated experiences related to the discharge planning of homeless patients. In addition, they may have community health 
Table 3 Risk-Adjusted Rates of 30-Day Readmissions and Emergency Department Visits After Hospital Discharge, by Homeless Status and Site of Care

\begin{tabular}{|c|c|c|c|c|c|c|c|}
\hline & \multirow[b]{2}{*}{$\begin{array}{l}\text { No. of } \\
\text { patients }\end{array}$} & \multicolumn{3}{|l|}{ Model 1* } & \multicolumn{3}{|l|}{ Model $2^{\dagger}$} \\
\hline & & $\begin{array}{l}\text { Adjusted rate, \% } \\
(95 \% \text { CI) }\end{array}$ & $\begin{array}{l}\text { Adjusted OR } \\
\text { (95\% CI) }\end{array}$ & $\begin{array}{l}p \\
\text { value }\end{array}$ & $\begin{array}{l}\text { Adjusted rate, \% } \\
(95 \% \text { CI) }\end{array}$ & $\begin{array}{l}\text { Adjusted OR } \\
(95 \% \text { CI) }\end{array}$ & $\begin{array}{l}p \\
\text { value }\end{array}$ \\
\hline \multicolumn{8}{|l|}{ Readmission rate } \\
\hline Homeless & 134,755 & $27.3(25.0,29.7)$ & $1.93(1.69,2.21)$ & \multirow{2}{*}{$\begin{array}{l}< \\
0.001\end{array}$} & $28.2(26.3,30.1)$ & $2.06(1.84,2.31)$ & \multirow[t]{2}{*}{$\stackrel{<}{0.001}$} \\
\hline $\begin{array}{l}\text { Non-homeless } \\
\text { Site of care }\end{array}$ & $3,392,628$ & $17.5(17.2,17.9)$ & Reference & & $17.5(17.3,17.8)$ & Reference & \\
\hline $\begin{array}{l}\text { Homeless-serving } \\
\text { hospitals }\end{array}$ & 377,654 & $17.9(16.6,19.1)$ & $0.99(0.89,1.09)$ & \multirow[t]{2}{*}{0.83} & $17.8(16.9,18.6)$ & $0.98(0.91,1.06)$ & \multirow[t]{2}{*}{0.63} \\
\hline $\begin{array}{l}\text { Non-homeless- } \\
\text { serving hospitals } \\
\text { Emergency departm } \\
\text { Homeless status }\end{array}$ & $\begin{array}{l}3,149,729 \\
\text { isit rate }\end{array}$ & $18.0(17.7,18.3)$ & Reference & & $18.1(17.7,18.3)$ & Reference & \\
\hline Homeless & 134,755 & $37.1(34.3,39.8)$ & $1.98(1.74,2.25)$ & \multirow[t]{2}{*}{$\begin{array}{l}< \\
0.001\end{array}$} & $37.7(35.1,40.2)$ & $2.04(1.82,2.30)$ & \multirow[t]{2}{*}{$\begin{array}{l}< \\
0.001\end{array}$} \\
\hline $\begin{array}{l}\text { Non-homeless } \\
\text { Site of care }\end{array}$ & $3,392,628$ & $23.6(23.3,23.9)$ & Reference & & $23.6(23.3,23.9)$ & Reference & \\
\hline $\begin{array}{l}\text { Homeless-serving } \\
\text { hospitals }\end{array}$ & 377,654 & $22.9(21.9,23.9)$ & $0.92(0.86,0.98)$ & \multirow[t]{2}{*}{0.01} & $23.3(22.3,24.3)$ & $0.94(0.88,1.00)$ & \multirow[t]{2}{*}{0.07} \\
\hline $\begin{array}{l}\text { Non-homeless- } \\
\text { serving hospitals }\end{array}$ & $3,149,729$ & $24.4(24.0,24.7)$ & Reference & & $24.3(24.0,24.6)$ & Reference & \\
\hline
\end{tabular}

OR odds ratio, CI confidence interval

We used multivariable logistic regression models. Standard errors were clustered at the hospital level to account for the potential correlation of patients treated at the same hospital. ORs of all-cause 30-day readmissions and emergency department visits are shown for each model. Adjusted rates were calculated using marginal standardization for each model

*Model 1 adjusted for patients' characteristics (the primary diagnosis for the admission, age, sex, racelethnicity, expected primary payer, and patient comorbidities), state dummies, and quarter dummies

† Model 2 additionally adjusted for discharge disposition, length of stay, and hospital characteristics

workers and/or patient advocates who have experience navigating homeless patients to the relevant information about other social security services, such as food stamp and homeless shelters. In contrast, hospitals that treat a smaller proportion of homeless patients may have less incentive to allocate resources to make sure that homeless patients receive appropriate care at discharge. Other possible explanations include that HSH may be working closely with homeless programs that provide shelters and healthcare and that the communities where HSH are located in may have better access to primary
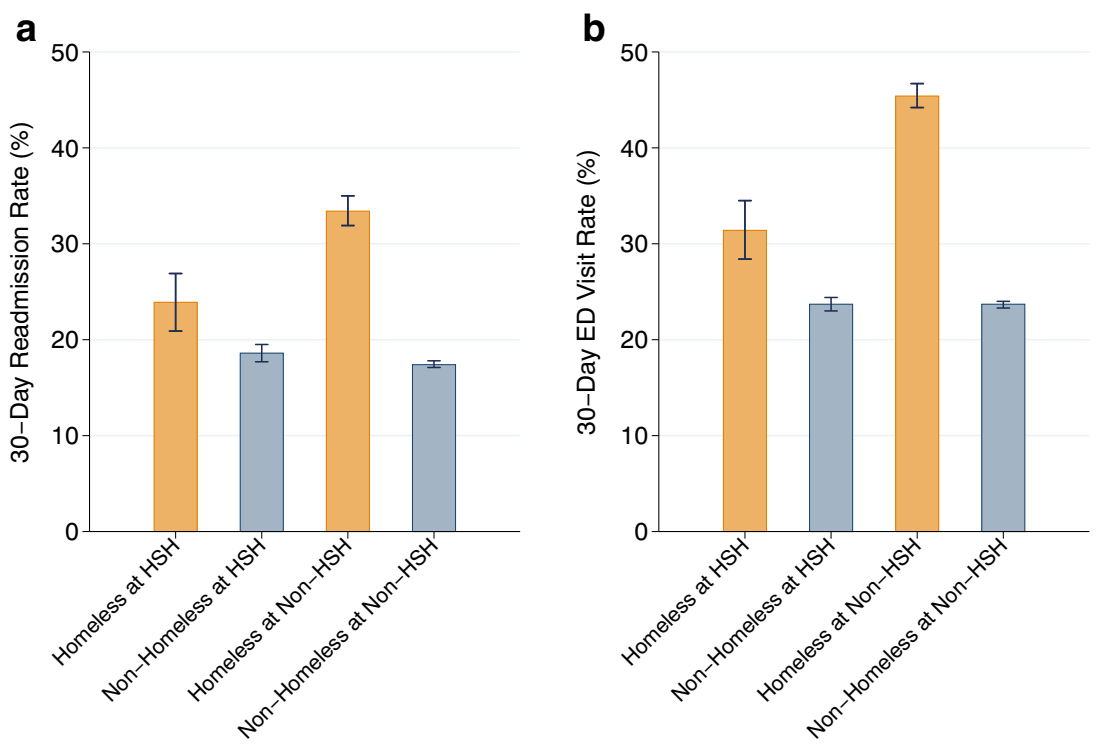

Fig. 1 Risk-adjusted rates of 30-day readmissions and emergency department visits after hospital discharge, by homeless status and site of care. HSH, homeless-serving hospitals. Panel a shows a 30-day risk-adjusted readmission rate estimated using marginal standardization (also known as predictive margins or margins of responses) for each group. Panel b shows a 30-day risk-adjusted ED visit rate estimated by marginal standardization. Logistic regression with standard errors clustered at hospital level was applied with adjustment for the primary diagnosis for the admission, age, sex, race/ethnicity, expected primary payers, comorbidity dummies, state dummies, and quarter dummies (Model 1). Error bars show the $95 \%$ confidence intervals. Considering multiple comparisons, the 30-day readmission rate or 30-day ED visit rate after hospital discharge was significantly different in each of the five pairs except the pair of non-homeless at HSH vs. non-homeless at non-HSH. 
care and other post-discharge resources (e.g., housing, shelter supply) for the homeless population.

Our findings were consistent with a small set of prior research suggesting higher rates of readmission and ED visits in the homeless population compared with the housed population. ${ }^{7-10}$ However, these studies were limited to a single city, and therefore, it remains largely unclear whether their findings are generalizable to other regions. These studies also did not adjust for risk factors of hospital visits such as comorbidities and primary diagnoses, and thus, their estimates may have been biased due to confounding (e.g., the homeless may have experienced worse outcomes only because they have more comorbidities and were sicker). Most recently, Wadhera and colleagues studied the inpatient database from 3 states and reported that the homeless patients have lower in-hospital mortality rates, longer mean length of stay, and lower mean costs per day compared with housed patients with similar demographics. ${ }^{5}$ However, this study did not examine readmissions and ED visits after hospital discharge among homeless patients, or whether the site of care (e.g., homeless-serving hospitals) affects these outcomes.

\section{LIMITATIONS}

First, as with any observational study, we could not fully account for unmeasured confounders, and homeless patients might be more likely to have unobserved severe conditions. It is also possible that non-HSH may be more selective about patients, and therefore, HSH may provide care to patients with more severe conditions than nonHSH. ${ }^{44}$ However, if this is the case, this would bias our estimates towards the null, and the true difference in patient outcomes between the HSH and non-HSH would be larger than what we have estimated. Second, the data on the homelessness were provided directly by hospitals to states in SID/SEDD databases, and therefore, there is the possibility of misclassification. ${ }^{45}$ However, hospitals have financial incentives to accurately collect information about the homelessness of their patients. Moreover, given that it is more likely that homeless patients were coded as non-homeless (we believe that the probability of nonhomeless patients to be coded as homeless is low), this misclassification would introduce a bias towards the null, and the true difference would be larger than what we have estimated if we could more accurately identify the homelessness. Third, our study was unable to identify the exact mechanisms through which HSH were achieving lower readmission and ED revisit rates. Our findings were qualitatively unchanged by adjustment for a set of hospital characteristics in Model 2, indicating that observed characteristics of hospitals available in our database do not explain the differences between HSH and non-HSH. Future research with more detailed information on HSH is warranted to understand why HSH treat homeless patients better. Lastly, because our analysis was restricted to homeless patients in the four states, our findings may not be generalizable to other states. However, these four states cover approximately $30 \%$ of the U.S. homeless population in $2014,{ }^{2}$ and the underlying mechanism as to how homeless patients are discharged from acute care hospitals may be similar across states.

\section{CONCLUSION}

In summary, using large population-based data across four U.S. states, we found higher rates of readmission and ED visit among the homeless population compared with the housed populations. The rates of readmissions and ED visits after hospital discharge were lower when homeless patients were treated at homeless-serving hospitals compared with when they were treated at other hospitals. Our findings highlight the importance of continued efforts to identify the mechanisms that cause the observed disparities in outcomes of homeless patients between hospitals. Such effort may, in turn, lead to the development and dissemination of optimal discharge planning for this large and vulnerable population.

Corresponding Author: Atsushi Miyawaki, MD, PhD; Department of Public Health, Graduate School of Medicine, The University of Tokyo, Tokyo, Japan (e-mail: amiyawaki-tky@umin.ac.jp).

Author Contributions Dr. Miyawaki had full access to the data in the study and takes responsibility for the accuracy and integrity of the data and its analyses.

Study concept and design: All authors.

Acquisition, analysis, or interpretation of data: All authors. Drafting of the manuscript: Miyawaki and Tsugawa.

Critical revision of the manuscript for important intellectual content: All authors.

Statistical analysis: All authors.

Administrative, technical, or material support: Tsugawa.

Study supervision: Tsugawa.

Funding Information This study was funded by St. Luke's International University, Tokyo, Japan.

\section{Compliance with Ethical Standards:}

The study was approved by the UCLA Institutional Review Board.

Conflict of Interest: The authors declare that they do not have a conflict of interest.

Disclaimer: The funder did not have any roles in the study design or the collection, analysis, or interpretation of the data.

\section{REFERENCES}

1. Fazel S, Geddes JR, Kushel M. The Health of Homeless People in High-Income Countries: Descriptive Epidemiology, Health Consequences, and Clinical and Policy Recommendations. Lancet. 2014;384(9953):1529-1540. https://doi.org/10.1016/S01406736(14)61132-6

2. Henry M, Mahathey A, Morrill T, Robinson A, Shivji A, Watt R. The 2018 Annual Homeless Assessment Report (AHAR) to Congress, Part 1: 
Point-in-Time Estimates of Homelessness. The U.S. Department of Housing and Urban Development; 2018.

3. United States Interagency Council on Homelessness. Opening Doors. Federal Strategic Plan to Prevent and End Homelessness, as Amended in $2015 ; 2015$.

4. National Coalition for the Homeless. How Many People Experience Homelessness?; 2009. https://www.nationalhomeless.org/factsheets/ How_Many.pdf. Accessed July 16, 2019.

5. Wadhera RK, Choi E, Shen C, Yeh RW, Joynt Maddox KE. Trends, Causes, and Outcomes of Hospitalizations for Homeless Individuals: A Retrospective Cohort Study. Med Care. 2019;57(1):21-27. https://doi org/10.1097/MLR.0000000000001015

6. National Coalition for the Homeless. Health care and homelessness. https://www.nationalhomeless.org/factsheets/health.html. Published 2009. Accessed August 15, 2019.

7. Saab D, Nisenbaum R, Dhalla I, Hwang Sw. Hospital Readmissions in a Community-Based Sample of Homeless Adults: a Matched-Cohort Study. J Gen Intern Med. 2016;31(9):1011-1018. https://doi.org/10.1007/ s11606-016-3680-8

8. Bharel M, Lin W-C, Zhang J, O'Connell E, Taube R, Clark RE. Health Care Utilization Patterns of Homeless Individuals in Boston: Preparing for Medicaid Expansion Under the Affordable Care Act. Am J Public Health. 2013;103(S2):S311-S317. https://doi.org/10.2105/ AJPH.2013.301421

9. Buck DS, Brown CA, Mortensen K, Riggs JW, Franzini L. Comparing Homeless and Domiciled Patients' Utilization of the Harris County, Texas Public Hospital System. J Health Care Poor Underserved. 2012;23(4):1660-1670. https://doi.org/10.1353/hpu. 2012.0171

10. Kushel MB, Perry S, Bangsberg D, Clark R, Moss AR. Emergency Department Use Among the Homeless and Marginally Housed: Results from a Community-Based Study. Am J Public Health. 2002;92(5):778 784. https://doi.org/10.2105/AJPH.92.5.778

11. Friedman B, Basu J. The Rate and Cost of Hospital Readmissions for Preventable Conditions. Med Care Res Rev. 2004;61(2):225-240. https:// doi.org/10.1177/1077558704263799

12. Hwang SW, Aubry T. Hospital costs and length of stay among homeless patients admitted to medical, surgical, and psychiatric services. Med Care. 2011:49(4):350-354.

13. Centers for Medicare \& Medicaid Services. Hospital Readmissions Reduction Program (HRRP). https://www.cms.gov/medicare/medicare-fee-for-service-payment/acuteinpatientpps/readmissions-reduction-program.html. Published January 16, 2019. Accessed July 18, 2019

14. Hospital Patient Discharge Process: Homeless Patients; 2018. https:// leginfo.legislature.ca.gov/faces /billTextClient.xhtml?bill_ id=201720180SB1152. Accessed August 22, 2019.

15. Tsai TC, Joynt KE, Orav EJ, Gawande AA, Jha AK. Variation in Surgical-Readmission Rates and Quality of Hospital Care. N Engl J Med. 2013;369(12):1134-1142. https://doi.org/10.1056/ NEJMsa 1303118

16. Yeh RW, Rosenfield K, Zelevinsky K, et al. Sources of Hospital Variation in Short-Term Readmission Rates after Percutaneous Coronary Intervention. Circ Cardiovasc Interv. 2012;5(2):227-236. https://doi.org/10 1161/CIRCINTERVENTIONS.111.967638

17. Hansen LO, Young RS, Hinami K, Leung A, Williams MV. Interventions to Reduce 30-Day Rehospitalization: A Systematic Review. Ann Intern Med. 2011;155(8):520-528. https://doi.org/10.7326/0003-4819-155-8201110180-00008

18. Texas Health Institute. Safety-Net Hospital Systems Transformation in the Era of Health Care Reform.; 2015. https://pdfs.semanticscholar.org/ 188f/e4e8f8fdb6943ac6318cd019c22bc056b379.pdf. Accessed August 30, 2019.

19. Kushel M. Things Fall Apart: Preventing High Readmission Rates Among Homeless Adults. J Gen Intern Med. 2016;31(9):985-986. https://doi org/10.1007/s11606-016-3744-9

20. The Healthcare Cost and Utilization Project. HCUP-US SID Overview. https://www.hcup-us.ahrq.gov/sidoverview.jsp. Published 2019. Accessed July 17, 2019.

21. The Healthcare Cost and Utilization Project. HCUP-US SEDD Overview. https://www.hcup-us.ahrq.gov/seddoverview.jsp. Published 2019 Accessed July 17, 2019.

22. American Hospital Association. AHA Annual Survey | American Hospital Association's Annual Survey Database | AHA Data Online. https://www. ahadataviewer.com/additional-data-products/AHA-Survey/. Published 2019. Accessed October 10, 2019.
23. Karaca Z, Wong HS, Mutter RL. Characteristics of Homeless and NonHomeless Individuals Using Inpatient and Emergency Department Services, 2008. U.S. Agency for Healthcare Research and Quality.; 2013:14. https://www.ncbi.nlm.nih.gov/books/NBK137747/pdf/Bookshelf_NBK137747.pdf. Accessed October 10, 2019.

24. Sun R, Karaca Z, Wong HS. Characteristics of Homeless Individuals Using Emergency Department Services in 2014. U.S. Agency for Healthcare Research and Quality.; 2017:13. https://www.hcup-us.ahrq.gov/ reports/statbriefs/sb229-Homeless-ED-Visits-2014.pdf. Accessed August 30, 2019.

25. Joynt KE, Orav EJ, Jha AK. Thirty-Day Readmission Rates for Medicare Beneficiaries by Race and Site of Care. JAMA. 2011;305(7):675-681 https://doi.org/10.1001/jama.2011.123

26. Tsai TC, Orav EJ, Joynt KE. Disparities in Surgical 30-day Readmission Rates for Medicare Beneficiaries by Race and Site of Care. Ann Surg. 2014;259(6):1086-1090. https://doi.org/10.1097/SLA. 0000000000000326

27. Barrett M, Steiner C, Andrew R, Kassed C, Nagamine M. Methodological Issues When Studying Readmissions and Revisits Using Hospital Administrative Data. U.S. Agency for Healthcare Research and Quality; 2011. https://www.hcup-us.ahrq.gov/reports/methods/2011_01.pdf. Accessed October 10, 2019.

28. Moore BJ, White $\mathbf{S}$, Coenen $\mathbf{N}$. Identifying increased risk of readmission and in-hospital mortality using hospital administrative data. Med Care. 2017;55(7):8.

29. Williams R. Using the Margins Command to Estimate and Interpret Adjusted Predictions and Marginal Effects. Stata J. 2012;12(2):308-331. https://doi.org/10.1177/1536867X1201200209

30. Stata.com. lrtest - Likelihood-ratio test after estimation. https://www. stata.com/manuals/rlrtest.pdf. Published 2019. Accessed August 13, 2019.

31. StataCorp. Stata Statistical Software: Release 15. College Station, TX, USA.: StataCorp LP.; 2017

32. Doran KM, Ragins KT, Gross CP, Zerger S. Medical Respite Programs for Homeless Patients: A Systematic Review. J Health Care Poor Underserved. 2013;24(2):499-524. https://doi.org/10.1353/ hpu.2013.0053

33. Sadowski LS, Kee RA, VanderWeele TJ, Buchanan D. Effect of a housing and case management program on emergency department visits and hospitalizations among chronically ill homeless adults: A randomized trial. JAMA. 2009;301(17):1771-1778.

34. Maness DL, Khan M. Care of the homeless: an overview. Am Fam Physician. 2014;89(8):634-640.

35. Lin W-C, Bharel M, Zhang J, O'Connell E, Clark RE. Frequent Emergency Department Visits and Hospitalizations Among Homeless People with Medicaid: Implications for Medicaid Expansion. Am J Public Health. 2015;105(S5):S716-S722. https://doi.org/10.2105/AJPH.2015. 302693

36. Gelberg L, Gallagher TC, Andersen RM, Koegel P. Competing Priorities as a Barrier to Medical Care Among Homeless Adults in Los Angeles. Am J Public Health. 1997;87(2):217-220. https://doi.org/10.2105/AJPH.87. 2.217

37. de Veer AJE, Stringer B, van Meijel B, Verkaik R, Francke AL. Access to Palliative Care for Homeless People: Complex Lives, Complex Care, BMC Palliat Care. 2018;17(1):119. https://doi.org/10.1186/s12904018-0368-3

38. Krumholz HM. Post-hospital Syndrome - An Acquired, Transien Condition of Generalized Risk. N Engl J Med. 2013;368(2):100-102. https://doi.org/10.1056/NEJMp1212324

39. Mackelprang JL, Qiu Q, Rivara FP. Predictors of Emergency Department Visits and Inpatient Admissions Among Homeless and Unstably Housed Adolescents and Young Adults: Med Care. 2015;53(12):1010-1017. https://doi.org/10.1097/MLR. 0000000000000436

40. McIntyre LK, Arbabi S, Robinson EF, Maier RV. Analysis of Risk Factors for Patient Readmission 30 Days Following Discharge from General Surgery. JAMA Surg. 2016;151(9):855. https://doi.org/10. 1001/jamasurg.2016.1258

41. Doran KM, Rahai N, McCormack RP, et al. Substance Use and Homelessness Among Emergency Department Patients. Drug Alcohol Depend. 2018;188:328-333. https://doi.org/10.1016/j.drugalcdep. 2018.04.021

42. Goldberg S. Medical Discharge Summary-"Disposition: To the Street." JAMA Intern Med. 2019. https://doi.org/10.1001/jamainternmed.2019. 3603 
43. Jha AK, Orav EJ, Epstein AM. The effect of financial incentives on hospitals that serve poor patients. Ann Intern Med. 2010;153(5):299306.

44. Joynt Maddox KE, Reidhead M, Hu J, et al. Adjusting for Social Risk Factors Impacts Performance and Penalties in the Hospital Readmissions Reduction Program. Health Serv Res. 2019;54(2):327-336. https://doi. org/10.1111/1475-6773.13133
45. Yamamoto A, Needleman J, Gelberg L, Kominski G, Shoptaw S, Tsugawa Y. Association Between Homelessness and Opioid Overdose and Opioid-Related Hospital Admissions/Emergency Department Visits. Soc Sci Med. 2019:112585. https://doi.org/10.1016/j.socscimed.2019. 112585

Publisher's Note: Springer Nature remains neutral with regard to jurisdictional claims in published maps and institutional affiliations. 